\title{
The Effect of Aptitude toward the Adaptability in Social Interaction
}

\author{
Yuniatri Intan Kusumaningrum \\ English Department Faculty of Humanities Jember University, Jember, Indonesia \\ intanyuniatri@gmail.com
}

\begin{abstract}
Social interaction is believed to be the catharsis of the success of English as L2 learning (Lightbown \& Spada, 2006). Sadly the practice of social interactions will be highly more challenging for learners coming from different cultures. The ability to adapt to new environment itself is a challenge, let alone the ability to be engaged in social interactions using the socially accepted language to facilitate the English learning. In short, international students studying English in Indonesia are truly in constant paradoxical situations, i.e. to improve their EFL they must interact with local students speaking local languages without which they cannot start the social interaction in the target language, EFL, which they may find lacking in themselves. This paper will try to uncover the reality experienced by some international students learning EFL in an Indonesian English institution. Using data triangulation method, it wants to see whether their initially presumed aptitude levels influence their adaptability that will further hamper their success in getting involved in the social interactions. The measurement of their English language aptitude employs Pimsleur Language Aptitude Battery (PLAB) (Lightbown \& Spada, 2006) incorporated by teachers' evaluation of the first year of studying EFL to clarify their self-perceived aptitude on EFL. Hopefully, the results can offer more formal means to both the students and institutions to see whether their aptitude level becomes significant factor in coping with the paradox.
\end{abstract}

Keywords: social interaction, adaptability, aptitude, international students, PLAB, EFL

\section{INTRODUCTION}

Perception that international students must establish their ability to be engaged in social interaction with local students seems to be paradoxical. It is apparent that social interaction plays important role since it is believed to be the catharsis of the success of English as L2 learning (Lightbown \& Spada, 2006). It is simply perceived that international students and social interaction are intricately interwoven so that one cannot separate the two without losing the significance of another. Through social interaction, the international students learn how to cope with new people, new culture, and new way of thinking. Besides, they also struggle facing socially accepted language to facilitate their English learning. In short, they must establish their ability to adapt to new environment in order to have the opportunity to start the social interaction.

The aforementioned prerequisite is the readiness of the learners to engage themselves in the future with the target language, English, facilitated by their sufficient local language with which they will gain access to the L2 community. In the context of L2 communities of English learners in Indonesia the language dominant as means of communication is the national language, Bahasa Indonesia. Despite being formalized as compulsory subject to introduce any international students studying in Indonesian institution, via language centers, it appears that the criteria for those international students in the mastery of Bahasa Indonesia are somehow insufficient. Many reasons underlying this mishap fall under budgetary, time allocation and lack of standardized tests, among others, to finally let the students go with their study. In many cases it is safe to assume that the training as such carried under the program adequately labelled 'Bahasa Indonesia bagi Penutur Asing' may have been administered to make use of the relatively short period prior to the start of the study terms. Compared to the many levels of, for example, 'bridging courses' in overseas universities in English speaking countries that prepare international students to compensate their IELTS or TOEFL IBTscore, BIPA program apparently run only for formality. Such assumption however may not represent and certainly not intended to criticize many universities in Indonesia running BIPA program. Without rigorous research on how much BIPA has been improved by researchers and practitioners in the recent years, such claim will certainly be an oversimplification.

Moving on to the capacity of the international students in English prior to the study of EFL itself, the samples in this study, internationalstudents consisting of three students(henceforth R1, R2, and R3) show that all of them have supposed that they need sufficient level of English from the very first place. With the relatively low self-efficacy in English it is probable that they will be consumed by the guilt of being unable to work in and out of the classroom learning. It is proven by the participants' relatively poor achievement during the first semester. The failure in the class should have been repaired by the quality learning they gain outside the classroom. However this has been equally unsuccessful. To make matters worse, almost all subjects they had during the first semester, despite carrying English names, e.g. speaking, writing, listening, reading, vocabulary, are still over reliant to the use of Bahasa Indonesia as the classroom language of instruction. In a personal interview, they said that they find their lack of having sufficient scores in most of English skill subjects. Thus, they presume that they had unsuccessful learning process. Those international presume leads to the consideration that it might be affected by their language aptitude. Language aptitude can be defined as a natural ability for learning an L2 and is believed to be in part related to general intelligence (Ellis, 1997).However, more relevant to discuss here is the preliminary level of English the students 
have. It is evident that the learning context outside the classroom, i.e. discussions and interactions with their Indonesian counterparts, should be best conducted in the language everyone is learning, EFL. Should they have sufficient level of Basic English, communication between them and local students should run sufficiently. In reality, the students used as participants of this research claim that they have not been successful in doing so, most notably because they assume that they do not have enough English to communicate themselves with their friends.

Another point that needs to take note is their ability to adapt to new environment. In this paper, the term adaptability is used to represent that definition. Addressing those points, this paper tries to unfold the influence of their presumption about their self-perceived aptitude on EFL toward their adaptability. Further, hopefully it is able to see whether it hampers their success in getting involved in social interaction.

\section{RESEARCH DESIGN AND METHOD}

To address some points that are highlighted in this paper, it needs to apply two analyses. The first analysis is the clarification of international students' presumption about their self-perceived aptitude on EFL. For this analysis, the research uses triangulation method i.e. a method which uses three kinds of data that relates to each other to reach the purpose. Those data are Pimsleur Language Aptitude Battery (PLAB) scores, teachers' evaluation of the first year of studying EFL, and their presumption. Meanwhile, for the second analysis, it describes the influence of aptitude level toward their adaptability. To do this analysis, it employs interview incorporated with the result of PLAB. Further, it also discusses whether it hampers their success in getting involved in social interaction.

\section{RESULT AND DISCUSSION}

\section{a. The language aptitude of the international students}

In this point, firstly the study needs to collect teachers' evaluation of the first year of studying EFL in the form of transcript scores. Secondly, those scores are used to denote the international students' learning ability. The denotation is determined in their second semester's scores. It goes under the consideration that the second semester is the latest achievement as data in this study. Besides, level of difficulty in the second semester is greater rather the first semester which gives more challenges to the students. After obtaining the transcript scores of all respondents, the four English skills scores from each respondent are presented into a table 1:
Yable 1. Table of The Grouping English Skills Scores

\begin{tabular}{cccc}
\hline English skills' subject & R1 & R2 & R3 \\
\hline LC.01 & $\mathrm{C}$ & $\mathrm{C}$ & $\mathrm{C}$ \\
\hline LC.02 & $\mathrm{C}$ & $\mathrm{D}$ & $\mathrm{D}$ \\
\hline $\mathrm{S} .01$ & $\mathrm{C}$ & $\mathrm{B}$ & $\mathrm{B}$ \\
\hline $\mathrm{S} .02$ & $\mathrm{~B}$ & $\mathrm{C}$ & $\mathrm{C}$ \\
\hline $\mathrm{W} .01$ & $\mathrm{C}$ & $\mathrm{D}$ & $\mathrm{D}$ \\
\hline $\mathrm{W} .02$ & $\mathrm{~B}$ & $\mathrm{D}$ & $\mathrm{D}$ \\
\hline $\mathrm{RC} .01$ & $\mathrm{D}$ & $\mathrm{D}$ & $\mathrm{D}$ \\
\hline $\mathrm{RC} .01$ & $\mathrm{~A}$ & $\mathrm{~B}$ & $\mathrm{~B}$ \\
\hline Source: Transcript Scores Published by the host faculty
\end{tabular}

The following step is expounding those English skills scores based on the table of standardization of assessment from table of standardization of assessment to typify the international students' learning ability. Since the achievement scores of R2 and R3 are the same, thus the assessment for those students is also the same. Following that assessment, the researcher develops assured points that R2 and R3are poor in listening comprehension and writing, good enough for speaking, and good for reading comprehension. Meanwhile, R1 achieves good for speaking and writing, good enough in listening comprehension, and excellent for reading comprehension.

After having the formal assessment of respondents, PLAB is then conducted. This kind of test is divided into six parts. First, in part 1, the respondents are asked to write their GPA of the first and second semester. Second, part 2 deals with level of interest in learning English. The respondents must indicate their degree of interest on the 5 boxes provided. It has written that number 1 is the lowest and number 5 is the highest level. Later, in part 3, the respondents were provided with 25 English words as the questions. They had to find the synonyms of the four word options which have approximately the same meaning. Forth, the respondents had to choose the right answer in part 4 i.e. language analysis. This part is divided into three units i.e. (i) countables and uncountables, (ii) pronouns, and (iii) some and any. Afterward, in part 5 i.e. about sound discrimination, it provides five recordings in one set of listening record which are recorded stories of different topics. In each recording, they must indicate the mentioned words which are spoken by the speakers. There are three similarly sounding words that are provided for the respondents to choose. One recording is used to answer three questions. There are fifteen questions in this listening section. The last part in PLAB is a listening section about sound-symbol association. The respondents had to listen one to threesyllables-English words from the recording. It has 30 English words as the questions. The respondents had to simply indicate which word was spoken by the speaker from the four printed alternatives.

In an attempt to elaborate the result of PLAB, the scores of the test of each respondent are assessed. The total scores of PLAB are made to be the equivalence of the standardized assessment score of the host faculty. The total score of PLAB is 100 points, i.e. the accumulation scores of 
each part of the test i.e. 25 points for part 3, 30 points for part 4,15 points for part 5 , and 30 points for part 6 .

$\mathrm{R} 1$, the male respondent got 78 points in this test. He is able to gain 20 points in part 3, 21 points in part 4,14 points in part 5 , and 23 points in part 6 . In part 1 , which is about the achievement in the first and second semester, R1reported 1.77 for his first semester and 2.29 for his second? Meanwhile, the question of interest in foreign language learning was answered by giving a tick in tick box number 3 .

In the meantime, R3obtains 51 total points. She got 7 points for part 3,17 points for part 4,8 points for part 5, and 19 points for part 6 . In part 1 , she wrote her GPA i.e. 2.14 for the first semester and 1.97 for the second semester. In addition, in part 2, in a five-point scale of interest in foreign language learning, she gave a tick in tick box number 2 .

R2 got away with the same score as R3did. She reached 51 total points for her test. Yet this score represents different wrong answer reference. $\mathrm{R} 2$ received5 points for part 3,15 points for part 4,7 points for part 5, and 24 points for part 6. Meanwhile in the first part, she reported 2.09 for first semester GPA and 1.63 for the second. In the next part, i.e. part which asked about the level of interest in foreign language learning, she has the same level of interest with R1. She ticked the box number 3 .

Through the results of PLAB, it is going to confirm the level of the proficiency of the respondents in English. Aptitude is a strong predictor of academic success. To do so, this paper uses triangulation method. In this method, it uses three kinds of data i.e. teachers' evaluation of the first year of studying EFL, PLAB scores, and the respondents' presumption. Based on the standardization of assessment from the host faculty, R2 and R3's scores in PLAB i.e. 51 falls between the ranges score 50-59.9 and are categorized as poor. Further, seeing their table, the researcher can draw a point thatR2 and R3's score in PLAB works linear with their achievement in English skills. Meanwhile, the score of PLAB of R1 i.e. 78 is located in the score scale 70-79.9 and is categorized as good. Besides, in R1's table, it is obviously seen that his achievement in English skills correlates with his score in PLAB.

GPA which is listed in each respondent's table is used as one of another criterion to predict the performance in foreign language courses. GPA is not only the best predictor of the achievement criterion but it is also a better prediction than the total PLAB scores. Based on Academic Guidance Book of the host faculty, students will be evaluated in the second semester to decide whether they deserve or not to continue their study through seeing their GPA. For Sarjana Degree, students must have at least 16 credit semesters without E score and GPA $\geq 2.00$.

Therefore, the assessment of GPA for R3 (1.97) and $\mathrm{R} 2$ (1.63) is classified as poor because their GPA is lower than the standard score of the second semester evaluation. On the other hand, GPA of R1 i.e. 2.29 is assessed as good enough because he is able to reach higher score from the standard score.
The last item in each respondent's table is degree of interest in foreign language learning. This item is the measurement of learner's motivation because it is a cognitive ability that would qualify to be a component of the aptitude complex. In other words, the researcher is able to infer that the higher respondent put his/her interest, the higher his/her motivation learning L2. Therefore, the general opinion which can be pulled out is that R1 and R2 have high motivation because they ticked the tick box number 3.Little bit contrary to them; R3 has quite high motivation because she ticked the tick box number 2 .

b. The elucidation of aptitude' influence toward respondents' adaptability.

Before discussing about the influence of aptitude toward respondents' adaptability, it is compulsory to elucidate the result of the interview. The interview is used to describe those international students' adaptability during their EFL study. First, this study needs to explore the relationship between the international students and their peers. In the first semester, they argued that they had assistance from their peers during learning process. They added that it is helpful since in the first semester, they really needed more help from their new friends. During the interview, all respondents argued that in the first semester, there were some Indonesian peers who came to their boarding house to visit them and other students for the same home country. Unfortunately, the numbers of Indonesian peers who visited them decreased in the second semester. The researcher supposes that this kind of attitude of Indonesian peers is caused by the euphoria to have foreign friends. They were encouraged to know more about their international students' fellow so that they visited them to have more intimate communication.

Besides, those respondents also confessed that their peers started to minimize their helps to them. Therefore, since in the second semester, those respondents did a lot of study by themselves. This attitude is supposed as the result of the way they interact with Indonesian which is all about inconveniences.

Additionally, they also rarely had group discussion with Indonesian peers. They will have it if only they had particular assignment to doing groups as their teacher required them to. They convinced that group discussion did not give much contribution to them in terms of learning process. Ideally, group discussion is a good forum to develop their academic skills and also their adaptability with their peers. Within this forum, indirectly, they will have to engage themselves personally and emotionally with how their peers react to them.

Addressing this situation, those respondents felt disappointed with the change of attitude from Indonesian peers. They emphasized that she truly needed their peers a lot to motivate their study. They also needed them to help overcome any obstacles during learning process. They argued that mostly, they preferred to be silent. They did not talk if their friend did not ask to them. They were ashamed to join their friend's conversation. Further, it can be highlighted that 
how the Indonesian peers reaction affects the way they build their adaptability. Besides, they also said that all these matters convincingly affected their motivation in learning L2.

Here, it appears that all respondents have passed two of four successive stages of culture shock by Brown (2007:195). Brown acknowledges the stage 1 as a period of excitement and euphoria over the newness of the surroundings. Earlier, the researcher is able to define that in the respondents' first semester, they were excited to know that many Indonesian peers and lecturers care about them. Nevertheless, it changed when they moved to second semester. In this semester, the researcher believes that they pass the second stage of culture shock, i.e. a condition which individuals feel the intrusion of more and more cultural differences into their own images of self and security (Brown, 2007:195). Brown adds that in this stage, individuals rely on and seek out the support of their fellow countrymen in the second culture, taking sympathy in complaining about local customs and conditions, seeking escape from their unpleasant experiences. Due to this, those respondents told that they were advised to keep their spirit and learn as best as they can when they told their experiences in EFL learning to the fellow of their home country. It is supposed that they want to look for protection and/or support.

The changing attitude from Indonesian peers, in fact, does not affect the attitude of the respondents. The respondents' attitude does not change since in the first semester i.e. they do not ever initiate to interact with their peers. Therefore, if in the second semester their attitude had been the same, it would have mean that even though their peers made less interaction, the respondents did not show the changing attitude toward that. In short, they could not do something for the sake up maintaining the good relationship with peers. In general, this kind of attitude is categorized as negative because they let the communication with their peers worsened without any initiative to ask or just keep in touch with their peers. Based on the study of John Oller and colleagues' research (see Oller, Hudson, \& Liu, 1977; Chihara \& Oller, 1978; Oller, Baca, \& Vigil, 1978), second language learner can gain benefit if they have positive attitudes while negative attitudes may lead to unsuccessful attainment of proficiency.

\section{CONCLUSION}

The result of this study shows that R1 has good assessment both for English skills' score and PLAB score. In addition, his GPA i.e. 2.29 is a safe score and his motivation in learning L2 is high. For the rest of the respondents, i.e. R2 and R3, they had poor assessment because their scores of PLAB and English skills' scores are low. Besides, their GPA decreases in the second semester 2.14 to 1.97 for R3 and 2.09 to 1.63 for $\mathrm{R} 2$ which is regarded as poor grade. Their difference is only about their level of motivation. R2 has higher motivation than R3. Therefore, the respondents' assumption about their unsuccessful learning process is only valid to R2 and R3. R1 is still categorized as successful student.
Besides, from the analysis of interview's transcript from the respondents, the researcher concludes that they lack the adaptability so that it affects the way they interact with peers both inside and outside the classroom, their motivation, and also their method in learning. They said that they prefer to learn by themselves instead of having group discussion. Related to the result of PLAB, it is able to define that aptitude is not only predict the ability in learning language but also predict the ability of learner to develop their adaptation. Further, it is proved that it hampers their success in learning EFL. However, this study chooses not to touch upon the idea that such adaptability should have been a part of the Indonesian counterparts in showing good comity supposedly resulting from good intercultural communication understanding or that the host faculty should have been better equipped with better treatment of international students as part of its investment for promoting better learning situation as an attempt to be more internationalized institution for best accommodation of the research data.

\section{REFERENCES}

Brown, H. D. (2007). Principles of Language Learning and Teaching Fifth Edition. White Plains, NY: Pearson Longman.

Chihara, T. \& Oller, J. (1978).Attitudes and Proficiency in EFL: a Sociolinguistics Study of Adult Japanese Speakers. Language learning, 28, 55-68.

Ellis, R. (1997). Second Language Acquisition. New York: Oxford University Press.

Lightbown, P. M., \& Spada, N. (2006). How Language are Learned Third Edition. Oxford: Oxford University Press.

Oller, J., Baca, L., \& Vigil, A. (1978). Attitudes and Attained Proficiency in ESL: A Sociolinguistics Study of Mexican-Americans in the Southwest. TESOL Quarterly, 11, 173-183.

Oller, J., Hudson, A., \& Liu, P. (1977). Attitudes and Attained Proficiency in ESL: A Sociolinguistics Study of Native Speakers of Chinese in United States. Language Learning, 27, 1-27. 